\title{
Assessing the current status of water sources for domestic and agricultural purposes in Ia Grai district, Gia Lai province
}

\author{
Tuan Q. Le ${ }^{1 *}$, Quy N. Le ${ }^{2}, \&$ Han T. N. Le ${ }^{1}$ \\ ${ }^{1}$ Faculty of Environment and Natural Resources, Nong Lam University, Ho Chi Minh City, Vietnam \\ ${ }^{2}$ People's Committee of Ia Grai District, Gia Lai
}

\section{ARTICLE INFO}

\section{Research Paper}

Received: October 23, 2019

Revised: November 22, 2019

Accepted: December 28, 2019

\section{Keywords}

Agriculture

Ia Grai district

Water source

Water quality

\section{${ }^{*}$ Corresponding author}

Le Quoc Tuan

Email: quoctuan@hcmuaf.edu.vn

\section{ABSTRACT}

Ia Grai district is located in the remote area of Gia Lai province. The income mostly relies on agricultural activities. However, the water shortage for agriculture is an issue and the irrigation much relies on the seasonal rainfall. This study aimed to figure out the demand for water use and other sources of water for irrigation. Household interview, water quality testing and field survey were conducted at 3 communes: Ia Kha, Ia Hrung and Ia To due to their largest agricultural area. The results showed that surface water had good quality; groundwater was polluted by microorganism but in the acceptable levels. All the water indicators met the national standard for the domestic purpose (column A1) and for agricultural irrigation (QCVN 39:2011/BTNMT). Based on the current demand for water use, the amount of water needs in 2020 was estimated as well as the solutions for water management and protection was also proposed for Ia Grai district.

Cited as: Le, T. Q., Le, Q. N., \& Le, H. T. N. (2020). Assessing the current status of water sources for domestic and agricultural purposes in Ia Grai district, Gia Lai province. The Journal of Agriculture and Development 19(1), 77-85. 


\title{
Đánh giá hiện trạng nguồn nước phục vụ cho sinh hoạt và phát triển nông nghiệp tại huyện Ia Grai, tỉnh Gia Lai
}

\author{
Lê Quốc Tuấn ${ }^{1 *}$, Lê Ngọc Quý ${ }^{2}$ \& Lê Trương Ngọc Hân ${ }^{1}$ \\ ${ }^{1}$ Khoa Môi trường và Tài Nguyên, Trường Đại Học Nông Lâm TP.HCM, TP. Hồ Chí Minh \\ ${ }^{2}$ Uỷ Ban Nhân Dân Huyện Ia Grai, Gia Lai
}

\section{THÔNG TIN BÀI BÁO}

Bài báo khoa học

Ngày nhận: 23/10/2019

Ngày chỉnh sửa: 22/11/2019

Ngày chấp nhận: 28/12/2019

Từ khóa

Chất lượng nước

Huyện Ia Grai

Nguồn nước

Nông nghiệp

*Tác giả liên hệ

Lê Quốc Tuấn

Email: quoctuan@hcmuaf.edu.vn

\section{TÓM TẮT}

Ia Grai là một huyện vùng sâu của tỉnh Gia Lai. Kinh tế người dân phụ thuộc chủ yếu vào hoạt động nông nghiệp. Tuy nhiên, nguồn nước cho nông nghiệp ở đây rất khan hiếm; phần lớn phụ thuộc vào nước mưa cho hoạt động tưới tiêu. Nghiên cứu này nhằm tìm hiểu nhu cầu sử dụng nước của người dân và các nguồn nước có khả năng sử dụng cho tưới tiêu. Phỏng vấn nông hộ, kiểm định chất lượng nước và khảo sát thực địa đã được thực hiện tại 3 xã có diện tích nông nghiệp lớn nhất trong huyện là Ia Kha, Ia Hrung và Ia Tô. Kết quả cho thấy nước mặt có chất lượng tốt, nước ngầm bị nhiễm vi sinh nhẹ nhưng tất cả các chỉ tiêu chất lượng nước đều đạt quy chuẩn cho phép của nước sử dụng cho mục đích sinh hoạt (cột A1) và hoạt động tưới tiêu (QCVN 39:2011/BTNMT). Dựa vào nhu cầu sử dụng nước hiện tại, đề tài dự báo lượng nước cần đến năm 2020, đồng thời đề xuất các giải pháp quản lý và bảo vệ nguồn nước cho huyện Ia Grai.

\section{1. Đặt Vấn Đề}

Ia Grai là huyện miền núi thuộc tỉnh Gia Lai. Tổng diện tích tự nhiên $1.103,81 \mathrm{~km}^{2}$, dân số trung bình năm 2018 là 94.803 người, mật độ dân số 85,89 người $/ \mathrm{km}^{2}$ (bằng $7,23 \%$ về diện tích và $7,04 \%$ dân số toàn tỉnh). Kinh tế phụ thuộc phần lởn vào hoạt động sản xuất nông nghiệp.

Tài nguyên nước mặt tại Ia Grai rất hạn chế, chủ yếu là từ các con suối lớn và hệ thống những dòng suối nhỏ nằm rải rác trên địa bàn huyện (GLDONRE, 2013). Do nằm ở độ cao thấp nên khả năng cung cấp nước để phục vụ sản xuất và sinh hoạt còn rất nhiều hạn chế (Ho, 2002). Nguồn nước ngầm của huyện cũng chủ yếu tập trung trong các núi đá, thác, có trữ lượng nhỏ và khó khai thác. Vào mùa khô, tình trạng thiếu nước thường xuyên diễn ra tại một số xã trong địa bàn (Ho, 2006). Người dân phải sử dụng nước mưa tận dụng được từ mùa mưa, gây khó khăn cho hoạt động sinh hoạt và không chủ động được trong hoạt động tưới tiêu (Ho, 2003; Ho \& ctv., 2007). Theo thống kê về tài nguyên nước tỉnh Gia Lai năm 2018, lượng nước cần thiết để cung ứng cho các nhu cầu khác nhau của huyện Ia Grai hơn $12.000 \mathrm{~m}^{3} /$ ngày. Tuy nhiên, lượng nước cấp cho các hoạt động này không đồng đều theo các mùa trong năm. Mùa mưa thì lượng nước cấp rất lớn, đôi khi còn gây ra lũ lụt, mùa khô thì thiếu nước trầm trọng.

Vì vậy, việc đánh giá hiện trạng, chất lượng nguồn nước nhằm phục vụ cho phát triển nông nghiệp tại huyện Ia Grai, tỉnh Gia Lai là rất cần thiết.

\section{Vật Liệu và Phương Pháp Nghiên Cứu}

\subsection{Phỏng vấn nông hộ}

Một trăm hộ dân khai thác, sử dụng nước cho nông nghiệp trên địa bàn 3 xã Ia Kha, Ia Hrung và Ia Tô đã được phỏng vấn với tỷ lệ số phiếu 
tương ứng với dân số của 3 huyện là 33,29 và 38 phiếu.

Nội dung phỏng vấn: đặc điểm kinh tế xã hội hộ; hiện trạng quản lý, khai thác, sử dụng nước cho nông nghiệp.

\subsection{Khảo sát, lẫy mẫu, bảo quản và phân tích}

Lấy mẫu nước tại các công trình thuỷ lợi, giếng nước trên địa bàn huyện vào mùa khô (tháng 1 đến tháng 6 ) và mùa mưa (tháng 7 đến tháng 12 ) để đánh giá sự biến đổi chất lượng nước theo thời gian. Quy trình lấy, bảo quản và phân tích mẫu tuân theo các tiêu chuẩn kỹ thuật Việt Nam. Mẫu nước được lấy, vận chuyển, lưu trữ và phân tích bởi Trung Tâm Kỹ thuật Đo lường Chất lượng Gia Lai.

Nước mặt: Vị trí lấy mẫu nước mặt được trình bày ở Bảng 1.

Nước ngầm: Vị trí lấy mẫu nước ngầm được trình bày ở Bảng 2 .

Thời gian lấy mẫu: 12 mẫu/2 đợt, lấy cùng một vị trí hoặc cách vị trí cũ khoảng $150 \mathrm{~m}$.

Ngày 25/02/2018: Mùa khô lấy 3 mẫu nước mặt và 3 mẫu nước ngầm.

Ngày 06/11/2018: Mùa mưa lấy 3 mẫu nước mặt và 3 mẫu nước ngầm.

\subsection{Xử lý số liệu}

Sử dụng các QCVN liên quan để làm tham số đối chiếu; số liệu được tổng hợp, xử lý bằng excel.

\section{Kết Quả và Thảo Luận}

\subsection{Tài nguyên nước và hiện trạng khai thác, sử dụng nước}

Về nước mặt, hệ thống suối: Ia Chăm, Ia Bơ Lăng, Ia Kha, Ia Năng, Ia Bol, Ia Nhing,... là nguồn dự trữ và cung cấp nước mặt chủ yếu. Về nước ngầm, huyện Ia Grai có tổng số giếng đào là 18.498 giếng, chiếm $6,43 \%$ tổng số giếng đào tỉnh Gia Lai.

Bảng 3 cho thấy hình thức khai thác nước ngầm thông dụng nhất là giếng đào và giếng khoan. Tổng số hộ sử dụng giếng đào lên tới $83 \%$. Các giếng đào thường có độ sâu trung bình $16 \mathrm{~m}$ - $25 \mathrm{~m}$. Tuy nhiên, có những giếng nằm trong khu vực thung lũng trũng thấp chỉ đào vài $3 \mathrm{~m}-6 \mathrm{~m}$. Các giếng đào thường có đường kính 1,2 m - 1,5 m nhưng đối với giếng đào do nhà nước đầu tư cho người dân sử dụng thì đường kính mở rộng hơn ở miệng giếng khoảng $3 \mathrm{~m}-5 \mathrm{~m}$. So với giếng đào thì tỉ lệ giếng khoan còn rất ít, chiếm $12 \%$, các giếng khoan thường có độ sâu khoảng $65-110$ m. Số còn lại khoảng $5 \%$ không sử dụng nước giếng đào hay giếng khoan mà sử dụng "giọt" nước để ăn uống và sinh hoạt, đây là nét văn hóa của những người dân tộc thiểu số. Hầu hết người dân sử dụng giếng tự đào $(87 \%)$ còn lại nhà nước đầu tư $(8 \%)$ và "giọt nước" là $5 \%$. Việc sử dụng nước ngầm cho các mục đích khác nhau có ảnh hưởng đến xu hướng hạ thấp mực nước ngầm theo mùa và theo năm $(\mathrm{Le} \& \mathrm{Vu}, 2014)$.

Hình 1 cho thấy người dân sử dụng nước cho các mục đích sinh hoạt nấu ăn chiếm $54 \%$, tắm giặt $29 \%$. Nước sử dụng cho tưới tiêu, chăn nuôi chiếm $10 \%$ và các dịch vụ khác liên quan đến nông nghiệp 7\%. Do thiếu nước, nhu cầu sử dụng nước ngầm là thực sự cần thiết với sinh hoạt hàng ngày của người dân.

\subsection{Chất lượng nguồn nước mặt và nước ngầm}

\subsubsection{Nước mặt}

Bảng 4 cho thấy tất cả các chỉ tiêu nằm trong giới hạn cho phép, phù hợp cho mục đích tưới tiêu nông nghiệp $\mathrm{B} 1$. Hơn nữa, các chỉ tiêu còn nằm trong giới hạn quy định sử dụng cho mục đích A1 - Sử dụng cho mục đích cấp nước sinh hoạt.

Bảng 5 thấy các chỉ tiêu chất lượng nước mặt vào mùa mưa đạt theo QCVN 08MT:2015/BTNMT. Riêng chỉ tiêu pH mặc dù vẫn nằm trong quy chuẩn nhưng ở cận dưới, sát với ngưỡng thấp theo quy chuẩn $5,5-9$. Cụ thể tại $3 \mathrm{khu}$ vực lần lượt là 5,$58 ; 5,75$ và 5,89 . Độ $\mathrm{pH}$ thấp sẽ ảnh hưởng đến năng suất cây trồng cũng như tính axit trong nước có khả năng ăn mòn kim loại từ đường ống, vật chứa nước và tích lũy các ion kim loại trong nước gây ảnh hưởng đến hoạt động nông nghiệp.

\subsubsection{Nước ngầm}

Bảng 6 cho thấy các chỉ tiêu chất lượng nước ngầm đều nằm trong giới hạn cho phép $\mathrm{QCVN}$ 09-MT:2015/BTNMT - Quy chuẩn kỹ thuật quốc gia về chất lượng nước ngầm. Trong đó chỉ tiêu TDS, Nitrat (NO3-), Mn, độ cứng đều rất thấp cho thấy chất lượng nước rất tốt. Riêng chỉ tiêu Coliform vượt quy chuẩn từ 15 dến 22 lần. Kết quả nghiên cứu phù hợp với các kết quả quan trắc qua các năm 2010 - 2012 (Nguyen, 2012). 
Bảng 1. Vị trí lấy mẫu nước mặt

\begin{tabular}{clcc}
\hline Ký hiệu & Tên mẫu & Xã & Tọa độ \\
\hline NM1 & Nước mặt Hồ Ia Năng & Ia Kha & 433392,$3 ; 1544684$ \\
NM2 & Nước mặt Đập Ia Hrung & Ia Hrung & 432269,$5 ; 1552050,8$ \\
NM3 & Nước mặt Đập Ia Châm & Ia Tô & 423876,$5 ; 1540715$ \\
\hline
\end{tabular}

Bảng 2. Vị trí lấy mẫu nước ngầm

\begin{tabular}{clcc}
\hline Ký hiệu & Tên mẫu & Xã & Tọa độ \\
\hline NN1 & Nước giếng khoan Ia Năng & Ia Kha & 433357,$9 ; 1544772,8$ \\
NN2 & Nước giếng khoan Ia Hrung & Ia Hrung & 431953,$2 ; 1551798,8$ \\
NN3 & Nước giếng khoan Ia Châm & Ia Tô & 423268,$6 ; 1540617,7$ \\
\hline
\end{tabular}

Bảng 3. Hình thức khai thác, sử dụng nguồn nước ngầm

\begin{tabular}{ccccccc}
\hline TT & Hình thức khai thác & Xã Ia Kha & Xã Ia Hrung & Xã Ia Tô & Tổng & Tỉ lệ (\%) \\
\hline 1 & Giếng đào & 26 & 24 & 33 & 83 & 83 \\
2 & Giếng khoan & 5 & 4 & 3 & 12 & 12 \\
3 & "Giợt" nước & 2 & 1 & 2 & 5 & 5 \\
\hline
\end{tabular}

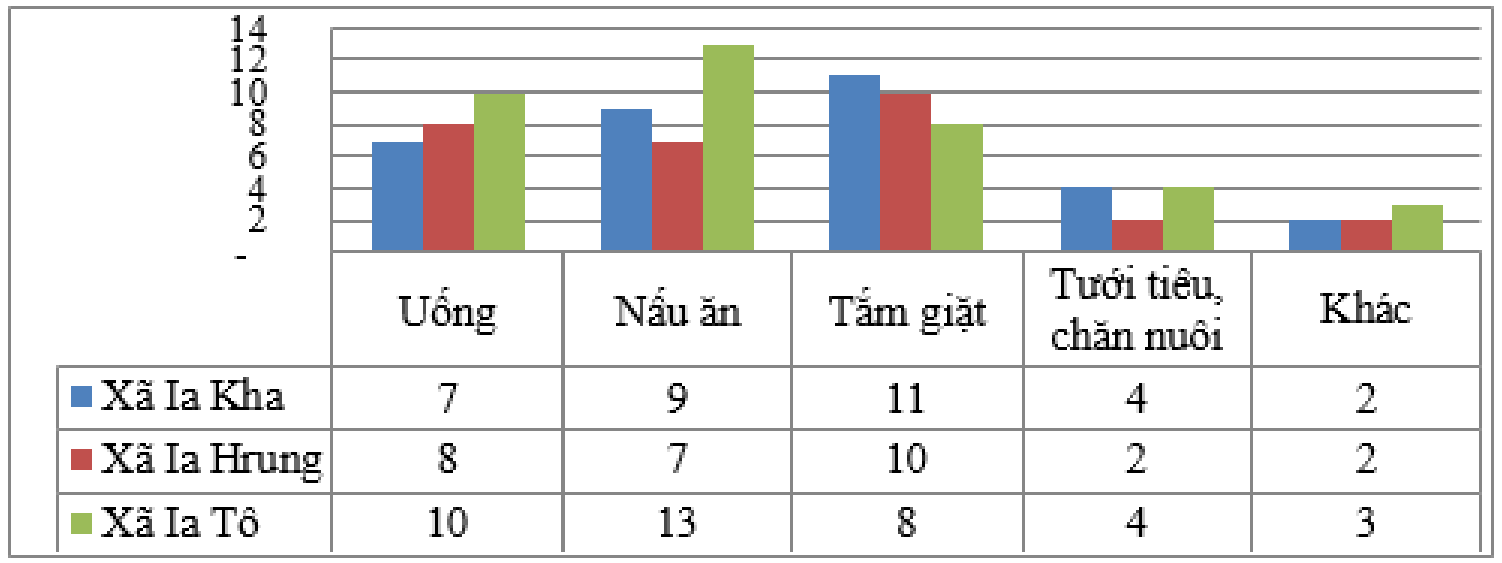

Hình 1. Tỉ lệ (\%) mục đích sử dụng nước ngầm.

Bảng 4. Chất lượng nước mặt đợt 1 vào mùa khô

\begin{tabular}{|c|c|c|c|c|c|c|}
\hline $\mathrm{TT}$ & Chỉ tiêu & Đơn vị & Mức quy định ${ }^{(*)}$ & NM1 & NM2 & NM3 \\
\hline 01 & $\mathrm{pH}$ & - & $5,5-9$ & 6,83 & 7,43 & 7,45 \\
\hline 02 & DO & $\mathrm{mg} / \mathrm{L}$ & $\geq 4$ & 7,25 & 7,65 & 8,05 \\
\hline 03 & $\mathrm{BOD}_{5}$ & $\mathrm{mg} / \mathrm{L}$ & $\leq 15$ & 2,02 & 0,81 & 1,61 \\
\hline 04 & COD & $\mathrm{mg} / \mathrm{L}$ & $\leq 30$ & 16,0 & 9,6 & 10,4 \\
\hline 05 & Phosphat $\left(\mathrm{PO}_{4}^{3-}\right)$ & $\mathrm{mg} / \mathrm{L}$ & $\leq 0,3$ & $\mathrm{KPH}$ & $\mathrm{KPH}$ & $\mathrm{KPH}$ \\
\hline 06 & Nitrat $\left(\mathrm{NO}_{3}^{-}\right)^{-}$ & $\mathrm{mg} / \mathrm{L}$ & $\leq 10$ & $\mathrm{KPH}$ & $\mathrm{KPH}$ & $\mathrm{KPH}$ \\
\hline 07 & Sunphat $\left(\mathrm{SO}_{4}^{2-}\right)$ & $\mathrm{mg} / \mathrm{L}$ & - & 14 & 8,64 & 11,64 \\
\hline 08 & Độ cứng & $\mathrm{mgCaCO}_{3} / \mathrm{L}$ & - & 10 & 7 & 7 \\
\hline 09 & $\mathrm{Mn}$ & $\mathrm{mg} / \mathrm{L}$ & $\leq 0,5$ & 0,016 & 0,018 & 0,019 \\
\hline 10 & As & $\mathrm{mg} / \mathrm{L}$ & $\leq 0,05$ & $\mathrm{KPH}$ & $\mathrm{KPH}$ & $\mathrm{KPH}$ \\
\hline
\end{tabular}


Bảng 5. Chất lượng nước mặt đợt 2 vào mùa mưa

\begin{tabular}{llccccc}
\hline TT & Chỉ tiêu & Đơn vị & Mức quy định ${ }^{(*)}$ & NM1 & NM2 & NM3 \\
\hline 01 & pH & - & $5,5-9$ & 5,58 & 5,75 & 5,89 \\
02 & DO & $\mathrm{mg} / \mathrm{L}$ & $\geq 4$ & 7,24 & 7,57 & 7,24 \\
03 & BOD & $\mathrm{mg} / \mathrm{L}$ & $\leq 15$ & $\mathrm{KPH}$ & 2,26 & $\mathrm{KPH}$ \\
04 & $\mathrm{COD}$ & $\mathrm{mg} / \mathrm{L}$ & $\leq 30$ & $\mathrm{KPH}$ & 16,00 & $\mathrm{KPH}$ \\
05 & Phosphat $\left(\mathrm{PO}_{4}^{3-}\right)$ & $\mathrm{mg} / \mathrm{L}$ & $\leq 0,3$ & $\mathrm{KPH}$ & $\mathrm{KPH}$ & 1,625 \\
06 & Nitrat $\left(\mathrm{NO}_{3}^{-}\right)$ & $\mathrm{mg} / \mathrm{L}$ & $\leq 10$ & 0,02 & $\mathrm{KPH}$ & $\mathrm{KPH}$ \\
07 & Sunphat $\left(\mathrm{SO}_{4}^{2-}\right)$ & $\mathrm{mg} / \mathrm{L}$ & - & 9,5 & 7,40 & 7,41 \\
08 & Độ cứng & $\mathrm{mgCaCO} / \mathrm{L}$ & - & 6,0 & 10,0 & 6,00 \\
09 & $\mathrm{Mn}$ & $\mathrm{mg} / \mathrm{L}$ & $\leq 0,5$ & 0,105 & 0,024 & 0,037 \\
10 & $\mathrm{As}$ & $\mathrm{mg} / \mathrm{L}$ & $\leq 0,05$ & $\mathrm{KPH}$ & $\mathrm{KPH}$ & $\mathrm{KPH}$ \\
\hline
\end{tabular}

(*) Theo QCVN 08-MT:2015/BTNMT - Quy chuẩn quốc gia về chất lượng nước mặt.

Bảng 6. Chất lượng nước ngầm đợt 1 vào mùa khô

\begin{tabular}{llccccc}
\hline TT & Chỉ tiêu & Đơn vị & Mức quy định ${ }^{(*)}$ & $\mathrm{NN} 1$ & $\mathrm{NN} 2$ & $\mathrm{NN} 3$ \\
\hline 01 & $\mathrm{pH}$ & - & $5,5-8,5$ & 6,44 & 6,47 & 6,54 \\
02 & TDS mg/L & $\leq 1500$ & 29 & 41 & 46 & \\
03 & Nitrat $\left(\mathrm{NO}_{3}^{-}\right)$ & $\mathrm{mg} / \mathrm{L}$ & $\leq 15$ & 0,04 & 0,058 & $\mathrm{KPH}$ \\
04 & Mn mg/L & $\leq 0,5$ & 0,051 & 0,035 & 0,082 & \\
05 & Độ cứng & $\mathrm{mgCaCO} / \mathrm{L}$ & $\leq 500$ & 9 & 16,7 & 15 \\
06 & Coliform & $\mathrm{MPN} / 100 \mathrm{~mL}$ & $\leq 3$ & 47 & 53 & 64 \\
07 & As & $\mathrm{mg} / \mathrm{L}$ & $\leq 0,05$ & $\mathrm{KPH}$ & $\mathrm{KPH}$ & $\mathrm{KPH}$ \\
\hline
\end{tabular}

(*) Theo QCVN 09-MT:2015/BTNMT - Quy chuẩn quốc gia về chất lượng nước ngầm.

Theo Bảng 7, các chỉ tiêu đều đạt QCVN 09MT:2015/BTNMT trừ hàm lượng Coliform vượt chuẩn 3 - 7 lần nhưng do được pha loãng nên giảm hơn so với mùa khô. Hàm lượng Coliform ở cả 3 vị trí quan trắc đều trắc đều vượt giới hạn cho phép do chất thải phát sinh từ hoạt động chăn nuôi gia súc, gia cầm bị thải trực tiếp ra môi trường.

\subsection{Dự báo nhu cầu khai thác, sử dụng và phát thải nước đến năm 2020}

\subsubsection{Hoạt động sinh hoạt}

Tốc độ tăng trưởng dân số đạt 1,9\%/năm giai đoạn 2019 - 2020. Với định mức cấp nước 100 lít/người/ngày, ước tính nhu cầu cấp nước và lưu lượng nước thải tại Bảng 8.

Theo Bảng 9, lưu lượng nước thải tại khu vực thành thị năm 2018 là $1.241,40 \mathrm{~m}^{3} /$ ngày, năm 2019 là $1.331,15 \mathrm{~m}^{3} /$ ngày và năm 2020 là $1.455,25$ $\mathrm{m}^{3} /$ ngày.

Năm 2018 với số dân thành thị 10.346 người, năm 2019 là 11.093 người và năm 2020 với số dân dự kiến 12.127 người. Tải lượng ô nhiễm trong nước thải sinh hoạt sau xử lý sơ bộ phát sinh hàng ngày được ước tính theo phương pháp đánh giá nhanh (WHO, 2003) tại Bảng 10. Bảng 11 cho thấy nồng độ các chất ô nhiễm vượt $\mathrm{QCVN}$ 14:2008, cột B.

\subsubsection{Hoạt động công nghiệp}

Lượng nước dùng cho sản xuất công nghiệp ước tính trung bình khoảng $30 \mathrm{~m}^{3} / 1$ ha/ngày đêm. Như vậy, tổng lưu lượng nước cấp cho công nghiệp của huyện Ia Grai năm 2018 là $1.056 \mathrm{~m}^{3} /$ ngày đêm, tương ứng với lượng nước thải là 844,8 $\mathrm{m}^{3} /$ ngày đêm. Bảng 12 . Dự báo lượng nước thải công nghiệp qua các năm

Bảng 13 cho thấy đến năm 2020, mỗi ngày hoạt động sản xuất công nghiệp của huyện sẽ thải ra các nguồn tiếp nhận khoảng: $23 \mathrm{~kg}$ SS; $70 \mathrm{~kg}$ $\mathrm{BOD}_{5} ; 34 \mathrm{~kg}$ COD; $3,4 \mathrm{~kg}$ Nitơ và $2,2 \mathrm{~kg}$ Photpho. Tải lượng ô nhiễm này tăng lên gấp 1,66 lần so với năm 2018. Cùng với nước thải sinh hoạt khu vực đô thị, đây cũng là một áp lực lớn đối với chất lượng các nguồn nước mặt trên địa bàn huyện, nếu như không có biện pháp kiểm soát triệt để. Các số liệu tính toán phù hợp với các kết quả tính toán tải lượng của hoạt động công nghiệp tại thành phố Biên Hòa, tỉnh Đồng Nai năm 2014 (Pham \& Le, 2014). 
Bảng 7. Chất lượng nước ngầm đợt 2 vào mùa mưa tại huyện Ia Grai

\begin{tabular}{llccccc}
\hline TT & Chỉ tiêu & Đơn vị & Mức quy định & NN1 & NN2 & NN3 \\
\hline 01 & pH & - & $5,5-8,5$ & 6,35 & 5,66 & 6,56 \\
02 & TDS & $\mathrm{mg} / \mathrm{L}$ & $\leq 1500$ & 17 & 31 & 39 \\
03 & Nitrat $\left(\mathrm{NO}_{3}^{-}\right)$ & $\mathrm{mg} / \mathrm{L}$ & $\leq 15$ & 0,02 & 0,04 & 0,06 \\
04 & Mn & $\mathrm{mg} / \mathrm{L}$ & $\leq 0,5$ & 0,056 & 0,045 & 0,035 \\
05 & Độ cứng & $\mathrm{mgCaCO} / \mathrm{L}$ & $\leq 500$ & 18,0 & 11,11 & 6 \\
06 & Coliform & $\mathrm{MPN} / 100 \mathrm{~mL}$ & $\leq 3$ & 10 & 12 & 17 \\
07 & As & $\mathrm{mg} / \mathrm{L}$ & $\leq 0,05$ & $\mathrm{KPH}$ & $\mathrm{KPH}$ & 0,003 \\
\hline
\end{tabular}

${ }^{(*)}$ Theo QCVN 09-MT:2015/BTNMT - Quy chuẩn quốc gia về chất lượng nước ngầm.

Bảng 8. Nhu cầu cấp nước và lưu lượng nước thải sinh hoạt

\begin{tabular}{ccccc}
\hline Năm & Dân số thành thị Định mức cấp nước & $\begin{array}{c}\text { Nhu cầu sử dụng } \\
\left(\mathrm{m}^{3} / \text { ngày }\right)\end{array}$ & $\begin{array}{c}\text { Lưu lượng nước } \\
\text { thải sinh hoạt } \\
\left(\mathrm{m}^{3} / \text { ngày }\right)\end{array}$ \\
\hline 2018 & 10.346 & 100 lít/người/ngày & $1.034,6$ & 827,68 \\
2019 & 11.093 & $1.109,3$ & 887,44 \\
2020 & 12.127 & & $1.212,7$ & 970,16 \\
\hline
\end{tabular}

Lưu lượng nước thải tính bằng $80 \%$ lượng nước cấp.

\subsubsection{Sinh hoạt tại nông thôn}

Lưu lượng nước thải khu vực nông thôn năm 2018 là $5.405,3 \mathrm{~m}^{3} /$ ngày, năm 2019 là 5.508 $\mathrm{m}^{3} /$ ngày và năm 2020 là $6.021,4 \mathrm{~m}^{3} /$ ngày (Bảng 14). Nước thải sinh hoạt được xử lý sơ bộ bằng các bể tự hoại. Hiện nay tại các khu vực nông thôn của huyện tỉ lệ hộ dân sử dụng bể tự hoại chỉ đạt khoảng 20\%. Theo quy hoạch của tỉnh năm 2020 phấn đấu đạt 50\%, tuy nhiên xét tình hình thực tế của huyện, ước tính đến năm 2020, tỉ lệ người dân sử dụng bể tự hoại tại các khu vực nông thôn chỉ đạt $40 \%$.

Bảng 15 và 16 cho thấy tải lượng ô nhiễm năm 2020 sẽ tăng lên nhiều so với năm 2018, nhưng nồng độ các chất ô nhiễm trong nước thải sinh hoạt năm 2020 lại giảm đi so với năm 2018. Nguyên nhân là do tăng lượng nước cấp và số hộ dân sử dụng bể tự hoại tại các khu vực nông thôn cũng tăng lên. Tuy vậy so sánh với tiêu chuẩn QCVN 14:2008/BTNMT, lượng nước thải sinh hoạt này sau khi xử lý sơ bộ bằng bể tự hoại vẫn còn chứa các thành phần gây ô nhiễm.

\subsubsection{Hoạt động chăn nuôi}

Lượng nước thải và tải lượng $\mathrm{BOD}$ trong hoạt động chăn nuôi được ước tính tại Bảng 17 và 18. Năm 2018, ước tính lưu lượng nước thải do hoạt động chăn nuôi của huyện Ia Grai là 2.083,7 m³ /ngày; năm 2019 là 2.266,62 m³ / ngày, gấp 1,09 lần so với năm 2018 và năm 2020 là 3.731,04 m³/ngày, gấp 1,79 lần so với năm 2018.

Hiện nay hoạt động chăn nuôi trên địa bàn huyện chủ yếu phát triển với quy mô nhỏ, lẻ nên việc quản lý lưu lượng nước thải này hạn chế. Tuy nhiên, theo quy hoạch phát triển nông nghiệp thì chăn nuôi là ngành kinh tế mũi nhọn, cần có các giải pháp chuẩn bị cho việc xử lý lượng lớn nước thải ô nhiễm hữu cơ cao.

Theo tính toán, lưu lượng nước thải tại khu vực đô thị của huyện lớn nhất năm 2018 là 1.306,32 $\mathrm{m}^{3} /$ ngày, năm 2020 là $1.455,25 \mathrm{~m}^{3} /$ ngày (Bảng 19). Dự báo từ nay đến 2020 vấn đề ô nhiễm nguồn nước mặt có thể xảy ra, chủ yếu sẽ ảnh hưởng đến các sông: Sông Sê San, sông Ia Grai cùng với hệ thống sông suối nhỏ và hệ thống nước ngầm của huyện. Các tính toán và dự báo phù hợp với kết quả tính toán lưu lượng và tải lượng nước thải của các hoạt động khác nhau đối với lưu vực sông Đồng Nai năm 2016 (Le \& Ngo, 2016).

\subsection{Giải pháp quản lý và bảo vệ nguồn nước}

\subsubsection{Ngăn ngừa nhiễm vi sinh}

Xây dựng nhà vệ sinh với bể tự hoại; nơi chăn nuôi gia súc cách xa giếng; tuyên truyền cho người dân về tác hại của nước nhiễm vi sinh; cung cấp dịch vụ hút bùn bể phốt; đối với các cơ sở sản xuất công nghiệp có nguồn nước thải thải vào nguồn tiếp nhận thì phải được phân tích, đánh 
Bảng 9. Dự báo nước thải tại khu vực thành thị của huyện Ia Grai

\begin{tabular}{lcccccc}
\hline \multirow{2}{*}{ Loại nước } & \multicolumn{3}{c}{ Lưu lượng nước cấp $\left(\mathrm{m}^{3} /\right.$ ngày $)$} & \multicolumn{3}{c}{ Lưu lượng nước thải $\left(\mathrm{m}^{3} / \mathrm{ngày}\right)$} \\
\cline { 2 - 7 } & 2018 & 2019 & 2020 & 2018 & 2019 & 2020 \\
\hline Nước sinh hoạt & $1.034,6$ & $1.109,3$ & $1.212,7$ & 827,68 & 887,44 & 970,16 \\
Nước công cộng & 103,46 & 110.93 & 121,27 & 82,71 & 88,74 & 97,02 \\
Nước TTCN & 103,46 & 110.93 & 121,27 & 82,71 & 88,74 & 97,02 \\
Nước rò rỉ (30\% Qsh) & 248,30 & 332,79 & 363,81 & 248,30 & 266,23 & 291,05 \\
\hline Tổng cộng & $1.489,82$ & $1.663,95$ & $1.819,05$ & $1.241,40$ & $1.331,15$ & $1.455,25$ \\
\hline
\end{tabular}

Bảng 10. Dự báo tải lượng ô nhiễm trong nước thải sinh hoạt tại khu vực thành thị

\begin{tabular}{cccc}
\hline \multirow{2}{*}{ Chỉ tiêu } & \multicolumn{3}{c}{ Tải lượng (kg/ngày đêm) } \\
\cline { 2 - 4 } & 2018 & 2019 & 2020 \\
\hline BOD $_{5}$ & $139,66-167,59$ & $149,76-179,71$ & $163,72-196,46$ \\
COD & $223,45-316,56$ & $239,61-339,45$ & $261,94-371,09$ \\
SS & $217,25-450,01$ & $232,95-482,55$ & $254,67-527,53$ \\
$\Sigma \mathrm{N}$ & $18,62-37,24$ & $26,62-39,94$ & $21,83-43,66$ \\
$\Sigma \mathrm{P}$ & $2,48-12,41$ & $2,75-13,31$ & $2,91-14,55$ \\
Dầu mỡ & $31,04-93,11$ & $33,28-99,84$ & $36,38-109,14$ \\
\hline
\end{tabular}

Bảng 11. Nồng độ ô nhiễm trong nước thải sinh hoạt khu vực thành thị

\begin{tabular}{ccccc}
\hline \multirow{2}{*}{ Chỉ tiêu } & \multicolumn{3}{c}{ Nồng độ $(\mathrm{mg} / \mathrm{L})$} & QCVN 14:2008 \\
\cline { 2 - 4 } & 2018 & 2019 & 2020 & Cột B \\
\hline BOD $_{5}$ & $112,5-135,0$ & $112,5-135,0$ & $93,95-135,0$ & 50 \\
$\mathrm{COD}$ & $180,0-255,0$ & $180,0-255,0$ & $180,0-255,0$ & - \\
$\mathrm{SS}$ & $175,0-362,5$ & $175,0-362,5$ & $175,0-362,5$ & 100 \\
$\Sigma \mathrm{N}$ & $15,0-30,0$ & $20,0-30,0$ & $15,0-30,0$ & - \\
$\Sigma \mathrm{P}$ & $2,0-10,0$ & $2,25-10,0$ & $2,0-10,0$ & 10 \\
Dầu mỡ & $25,0-75,0$ & $25,0-75,0$ & $25,0-75,0$ & 20 \\
\hline
\end{tabular}

Bảng 12. Dự báo lượng nước thải công nghiệp qua các năm

\begin{tabular}{ccccccc}
\hline \multirow{2}{*}{ Loại nước } & \multicolumn{2}{c}{$\begin{array}{c}\text { Diện tích đất } \\
\text { công nghiệp (ha) }\end{array}$} & $\begin{array}{l}\text { Lưu lượng nước } \\
\text { cấp }\left(\mathrm{m}^{3} / \text { ngày }\right)\end{array}$ & $\begin{array}{l}\text { Lưu lượng nước } \\
\text { thải }\left(\mathrm{m}^{3} / \mathrm{ngày}\right)\end{array}$ \\
\cline { 2 - 7 } & 2018 & 2020 & 2018 & 2020 & 2018 & 2020 \\
\hline Nước công nghiệp & 35,20 & 85,20 & 1.056 & 2.556 & 844,8 & $2.044,8$ \\
\hline
\end{tabular}

Lượng nước thải phát sinh bằng $80 \%$ lượng nước cấp sử dụng.

Bảng 13. Dự báo tải lượng ô nhiễm trong nước thải qua các năm

\begin{tabular}{ccccccc}
\hline Hệ số tải lượng o & & $\mathrm{SS}$ & $\mathrm{BOD}_{5}$ & $\mathrm{COD}$ & $\Sigma \mathrm{N}$ & $\Sigma \mathrm{P}$ \\
\cline { 2 - 7 } nhiễm $(\mathrm{kg} / \mathrm{ha} /$ ngày đêm $)$ & & 0,46 & 1,4 & 0,68 & 0,068 & 0,044 \\
\hline $\mathrm{Năm}$ & Diện tích (ha) & Tải lượng ô nhiềm & $(\mathrm{kg} / \mathrm{ngày}$ & đêm $)$ \\
\hline 2018 & 35,20 & 13,8 & 42 & 20 & 2,04 & 1,32 \\
2020 & 85,20 & 23 & 70 & 34 & 3,4 & 2,2 \\
\hline
\end{tabular}


Bảng 14. Dự báo nhu cầu cấp nước và lưu lượng nước thải sinh hoạt khu vực nông thôn

\begin{tabular}{ccccc}
\hline Năm & Dân số nông thôn & Định mức cấp nước & $\begin{array}{c}\text { Nhu cầu sử dụng } \\
\left(\mathrm{m}^{3} / \text { ngày }\right)\end{array}$ & $\begin{array}{c}\text { Lưu lượng nước } \\
\text { thải sinh hoạt } \\
\left(\mathrm{m}^{3} / \mathrm{ngày}^{1}\right.\end{array}$ \\
\hline 2018 & 10.346 & \multirow{2}{*}{ 80 lít/người/ngày } & $6.756,6$ & $5.405,3$ \\
2019 & 86.062 & & 6.885 & 5.508 \\
2020 & 94.085 & & $7.526,8$ & $6.021,4$ \\
\hline
\end{tabular}

${ }^{1}$ Lưu lượng nước thải tính bằng $80 \%$ lượng nước cấp.

Bảng 15. Dự báo tải lượng ô nhiễm trong nước thải sinh hoạt thải ra môi trường tại khu vực nông thôn

\begin{tabular}{ccccc}
\hline \multirow{2}{*}{ Chỉ tiêu } & Hệ số Tải lượng & \multicolumn{3}{c}{ Tải lượng (kg/ngày đêm) } \\
\cline { 3 - 5 }$(\mathrm{g} /$ người/ngày đêm $)$ & 2018 & \multicolumn{2}{c}{2019} & 2020 \\
\hline BOD $_{5}$ & $45-54$ & $1.140,58-1.368,69$ & $1.161,84-1.394,21$ & $1.270,15-1.524,18$ \\
COD & $72-102$ & $1.824,92-2.585,30$ & $1.858,94-2.633,50$ & $2.033,24-2.879,00$ \\
$\mathrm{SS}$ & $70-145$ & $1.774,23-3.675,19$ & $1.807,30-3.836,97$ & $1.975,79-4.092,99$ \\
$\Sigma \mathrm{N}$ & $6-12$ & $152,08-304,16$ & $154,91-309,82$ & $169,35-338,71$ \\
$\Sigma \mathrm{P}$ & $08-4$ & $20,28-101,39$ & $20,66-103,28$ & $22,58-112,90$ \\
Dầu mỡ & $10-30$ & $253,46-760,38$ & $258,19-767,46$ & $282,26-846,77$ \\
\hline
\end{tabular}

Bảng 16. Nồng độ ô nhiễm trong nước thải sinh hoạt khu vực nông thôn

\begin{tabular}{|c|c|c|c|c|}
\hline \multirow{2}{*}{ Chỉ tiêu } & \multicolumn{3}{|c|}{ Nồng độ (mg/L) } & \multirow{2}{*}{$\begin{array}{c}\text { QCVN 14:2008 } \\
\text { Cột B }\end{array}$} \\
\hline & 2018 & 2019 & 2020 & \\
\hline $\mathrm{BOD}_{5}$ & $207,08-248,49$ & $210,94-253,12$ & $210,94-253,12$ & 50 \\
\hline COD & $331,32-469,37$ & $337,50-478,12$ & $337,49-478,12$ & - \\
\hline $\mathrm{SS}$ & $322,12-677,25$ & $328,12-696,62$ & $328,12-679,68$ & 100 \\
\hline$\Sigma \mathrm{N}$ & $27,61-55,22$ & $28,12-56,25$ & $28,12-56,24$ & - \\
\hline$\Sigma \mathrm{P}$ & $3,82-18,41$ & $3,75-18,75$ & $3,74-18,74$ & 10 \\
\hline Dầu mỡ & $40,02-138,05$ & $46,86-139,33$ & $46,87-140,62$ & 20 \\
\hline
\end{tabular}

Bảng 17. Lượng nước thải trong hoạt động chăn nuôi

\begin{tabular}{|c|c|c|c|c|c|c|c|}
\hline \multirow{2}{*}{ Loài } & \multicolumn{3}{|c|}{ Số lượng } & \multirow{2}{*}{ Định mức } & \multicolumn{3}{|c|}{ Lượng nước thải (m³/ngày) } \\
\hline & 2018 & 2019 & 2020 & & 2018 & 2019 & 2020 \\
\hline Trâu, bò & 15.020 & 15.635 & 16.015 & 8 & 329,2 & 342,68 & 351,03 \\
\hline Heo & 28.550 & 32.786 & 37.687 & 14,6 & 1.142 & $1.311,44$ & $1.507,48$ \\
\hline Gia cầm & 101.600 & 244.401 & 759.414 & 0,9 & 612,50 & 612,50 & $1.872,53$ \\
\hline Tổng cộng & & & & & $2.083,7$ & $2.266,62$ & $3.731,04$ \\
\hline
\end{tabular}

Bảng 18. Tải lượng BOD trong nước thải chăn nuôi

\begin{tabular}{cccccccc}
\hline \multirow{2}{*}{ Loài } & \multicolumn{3}{c}{ Số lượng } & \multirow{2}{*}{ Định mức } & \multicolumn{3}{c}{ Tải lượng (tấn/năm) } \\
\cline { 2 - 4 } \cline { 7 - 8 } & 2018 & 2019 & 2020 & & 2018 & 2019 & 2020 \\
\hline Trâu bò & 15.020 & 15.635 & 16.015 & 164 & $2.463,28$ & $2.564,14$ & $2.626,55$ \\
Heo & 28.550 & 32.786 & 37.687 & 32,9 & 939,29 & $1.078,66$ & $1.239,9$ \\
Gia cầm & 101.600 & 244.401 & 759.414 & 1,61 & 163,57 & 399,93 & $1.222,66$ \\
\hline Tồng cộng & & & & $3.566,14$ & $4.042,73$ & $5.089,11$ \\
\hline
\end{tabular}


Bảng 19. Tổng lượng nước thải của huyện Ia Grai qua các năm

\begin{tabular}{lcccc}
\hline \multirow{2}{*}{ Lĩnh vực } & \multicolumn{2}{c}{2018} & \multicolumn{2}{c}{2020} \\
\cline { 2 - 5 } & $\begin{array}{c}\text { Lưu lượng } \\
\left(\mathrm{m}^{3} / \text { ngày }\right)\end{array}$ & Tỉ lệ $(\%)$ & $\begin{array}{c}\text { Lưu lượng } \\
\left(\mathrm{m}^{3} / \text { ngày }\right)\end{array}$ & Tỉ lệ $(\%)$ \\
\hline Nước thải khu vực đồ thị & $1.306,32$ & 13,55 & $1.455,25$ & 9,96 \\
Nước thải công nghiệp & 844,4 & 8,76 & $2.044,8$ & 13,99 \\
Nước thải sinh hoạt KV nông thôn & $5.405,3$ & 56,07 & $6.021,4$ & 41,21 \\
Nước thải chăn nuôi & $2.083,7$ & 21,62 & $5.089,11$ & 34,81 \\
\hline Tồng cộng & $9.639,72$ & 100 & $14.610,56$ & 100 \\
\hline
\end{tabular}

giá tình hình hoạt động sản xuất xả thải và có giấy phép xả thải vào môi trường nước.

\subsubsection{Giảm ô nhiễm nước}

Bằng phương pháp lắng và lọc; xây dựng nhà máy nước sạch, đặt trạm bơm, lấy nước từ hồ làng Dút, hồ Ia Kha, Suối Ia Kha, cầu Ia Châm, Suối Ia Tô, Suối Ia Deil. . . ; khuyến khích người dân sử dụng nước giếng khoan và đồng thời hướng dẫn phương pháp khoan và các thủ tục liên quan đến khai thác nước ngầm.

\subsubsection{Nâng cao hiệu quả công tác quản lý môi trường}

Kiểm tra cấp phép khoan giếng, đào giếng; định kỳ phân tích mẫu; có biện pháp xử lý việc tự ý khoan, đào giếng...

\section{Kết Luận}

Người dân sử dụng nước từ suối, "giọt nước", và các ao đập nhưng phụ thuộc chủ yếu vào nước ngầm cho sinh hoạt. Năm 2018, huyện có 18.498 giếng đào, tỷ lệ dùng giếng khoan là rất thấp.

Chất lượng nước mặt còn tương đối tốt. Các chỉ tiêu đều nằm trong giới hạn cho phép phù hợp cho mục đích tưới tiêu nông nghiệp B1 của QCVN 08-MT:2015/BTNMT - Quy chuẩn quốc gia về chất lượng nước mặt. Các chỉ tiêu còn nằm trong giới hạn quy định sử dụng cho mục đích A1 - Sử dụng cho mục đích cấp nước sinh hoạt. Đối với nước ngầm, các chỉ tiêu đều nằm trong giới hạn của QCVN 09-MT:2015/BTNMT - Quy chuẩn quốc gia về chất lượng nước ngầm. Trừ chỉ tiêu Coliform cả mùa mưa và mùa khô đều vượt ngưỡng cho phép (bị nhiễm vi sinh) nhưng ở mức độ nhẹ.

Trên cơ sở dự báo nhu cầu khai thác, sử dụng và phát thải khu vực thành thị, khu vực nông thôn, nước thải công nghiệp và nước thải chăn nuôi đến năm 2020, đề tài đề xuất 4 giải pháp quản lý, bảo vệ chất lượng nguồn nước tại huyện Ia Grai, tỉnh Gia Lai.

\section{Tài Liệu Tham Khảo (References)}

GLDONRE (Gia Lai Department of Natural Resources and Environment) (2013). Plan of water sources uses in Gia Lai province up to 2020. Gia Lai, Vietnam: GLDONRE.

Ho, M. T. (2002). Assessing water resources reserves in Gia Lai province. The $15^{\text {th }}$ Scientific Seminar of Hanoi University of Mining and Geology 3 (160-168). Ha Noi, Vietnam: Hanoi University of Mining and Geology.

Ho, M. T. (2003). Report on water balance, oriented water uses and water sources protection in Gia Lai province. Gia Lai, Vietnam: Gia Lai Annual Report.

Ho, M. T. (2006). Natural factors inpact on ground water levels in Gia Lai province. Journal of Geology 296, 2936 .

Ho, M. T., Bui, H., \& Nguyen, C. N. (2007). Impact of evaporation. $10^{\text {th }}$ Scientific workshop of Institute of Meteology Hydrology and Environment (50-58). Ha Noi, Vietnam: Institute of Meteorology Hydrology and Environment.

Le, Q. T., \& Ngo, T. K. (2016). Forecasting the water quality and the capacity of receiving wastewater of the Dong Nai river up to 2020. Journal of Science and Technology 54(2A), 1941-1948.

Le, Q. T., \& Vu, M. A. (2014). Evaluation groundwater pollution in Thuan An town, Binh Duong province and propose suitable management solution. Journal of Agricultural Sciences and Technology 1, 65-73.

Nguyen, T. H. (2012). Ground water quality monitoring in the first 6 months of 2012. Ha Noi, Vietnam: MONRE.

Pham, T. H., \& Le, Q. T. (2014). Evaluation of water quality of Dong Nai river across Dong Nai province and proposal management solution. Journal of Agricultural Science and Technology 2, 68-75.

WHO (World Health Organization). (2003). Domestic water quality, service, level and health. Geneva, Switzerland: WHO Press. 